\title{
Desenvolvimento de modelos matemáticos para a determinação da disponibilidade de luz natural no crepúsculo para a cidade de Belo Horizonte
}

\author{
Development of mathematical models to determine \\ daylight availability at twilight in the city of Belo \\ Horizonte
}

\begin{abstract}
Camila Carvalho Ferreira
Roberta Vieira Gonçalves Souza

\section{Resumo}

Camila Carvalho Ferreira Universidade Federal de Minas

Roberta Vieira Gonçalves Souza Universidade Federal de Minas Gerais Belo Horizonte - MG - Brasil

Recebido em 10/09/12 Aceito em 15/05/13

M

esmo quando o sol apresenta-se abaixo da linha do horizonte, há luz natural na atmosfera. $O$ presente trabalho expõe uma abordagem para a determinação da disponibilidade de luz natural durante o período crepuscular, por meio de modelos de regressão múltipla. Tais modelos aforam utilizados para estimar as horas necessárias de acionamento da iluminação pública artificial. Este estudo foi desenvolvido para a cidade de Belo Horizonte, MG, Brasil, levantando-se o período mensal de disponibilidade de iluminância. Os dados de iluminância global foram coletados pela Estação de Medição de Iluminação Natural (EMIN-BH). A análise de duração da noite em função dos modelos e tipos de céu foi feita aplicando-se os modelos desenvolvidos aos respectivos tipos de céu característicos para cada mês ao longo do ano. A duração da noite média medida foi de 11 h e 30 min, enquanto a predita pelos modelos foi de 11 h e 29 min, o que indica a adequação dos modelos desenvolvidos.

Palavras-chave: Disponibilidade de luz natural. Crepúsculo. Duração da noite.

\section{Abstract}

Even when the sun is below the horizon, daylight is present in the atmosphere. This paper presents an approach for determining daylight availability during twilight, using multiple regression models. These models were used to estimate the number of hours that require artificial public lighting. This study was conducted in the city of Belo Horizonte, Minas Gerais, Brazil, measuring the monthly period of illuminances availability. Global illuminance data were collected by the Daylight Measurement Station of Belo Horizonte (EMIN-BH). The analysis of night length, depending on the sky models and types, was done by applying the developed models to the types of sky characteristic for each month of the the year. The mean night duration measured was 11 hours and 30 minutes, while the predicted duration was 11 hours and 29 minutes, which indicates that the models developed were adequate.

Keywords: Daylight availability. Twilight. Night duration.
\end{abstract}




\section{Introdução}

Segundo o artigo 60 da Resolução ANEEL 456, de 29 de novembro de 2000, que substituiu a Portaria DNAEE 466, de 12 de novembro de 1997, e conforme a retificação publicada no Diário Oficial da União de 15 de dezembro de 2000, seção 1, v. 138, p. 142, no 241-E (AGÊNCIA..., 2008), a base de cálculo para encargo com iluminação pública em vigor é de $12 \mathrm{~h}$ diárias (mais especificamente $11 \mathrm{~h}$ e $50 \mathrm{~min}$, considerando o ano todo), determinadas com base na média anual de horas entre o pôr e o nascer do sol, ou seja, o período estimado desde o momento quando o sol desaparece no plano do horizonte até o momento em que ele desponta.

Porém, mesmo o sol estando abaixo da linha do horizonte, há ainda luz na atmosfera terrestre. Essa luz, denominada luz crepuscular, em certas ocasiões, é suficiente para não acionar os relés fotoelétricos que acendem (no ocaso) e apagam (na alvorada) as luminárias dos logradouros públicos, interferindo potencialmente no consumo de energia estimado pelas concessionárias.

Existem hoje diversos modelos matemáticos para predição da quantidade de luz natural disponível na abóbada celeste, para dada localidade e condição de céu. No entanto, grande parte dos estudos relacionados à disponibilidade de luz natural refere-se ao fenômeno do período em que o sol encontra-se acima da linha do horizonte, acima de $4^{\circ}$ de altura solar (INTERNATIONAL..., 2008), ou seja, ao longo do dia, quando ocorrem altos níveis de iluminância.

É de importância, então, a investigação local para o estabelecimento do período crepuscular, sendo a iluminação do crepúsculo marcadamente influenciada pela condição atmosférica e pelas condições meteorológicas através das condições de céu.

É inserido nesse contexto que o presente trabalho propõe-se a gerar modelos matemáticos capazes de quantificar a disponibilidade de iluminação natural para o período crepuscular, tendo como estudo de caso a cidade de Belo Horizonte, Minas Gerais, Brasil.

\section{A iluminação pública no Brasil}

Existem hoje no Brasil cerca de 15 milhões de pontos de iluminação pública, conforme o último levantamento cadastral realizado pelo Procel (2008), em 2008, nas distribuidoras de energia elétrica. Isso significa uma demanda de 2,2 GW e um consumo de 9,7 bilhões de $\mathrm{kWh} / \mathrm{ano}$, o que corresponde a 3,0\% do consumo total de energia elétrica do país.
A região Sudeste, da qual o estado de Minas Gerais faz parte, representa quase metade $(45 \%)$ dos pontos de iluminação pública do país (PROCEL, 2008), e Minas Gerais é responsável por cerca de $26,7 \%$ dos pontos de iluminação pública, o equivalente a aproximadamente 1,8 milhão de pontos, número que torna o estado representativo no que se refere à iluminação pública.

\section{Definição de crepúsculo}

O crepúsculo é definido como o período de luz natural parcial antes do nascer do sol ou depois do pôr do sol, isto é, quando o Sol encontra-se abaixo da linha do horizonte (LH), sendo decorrente da reflexão e espalhamento da luz solar pelas camadas superiores da atmosfera terrestre (MUNEER, 2004).

O crepúsculo pode ser caracterizado, a partir do ângulo zenital medido do zênite ao horizonte (inverso do ângulo de altura solar), como crepúsculo astronômico, crepúsculo náutico ou crepúsculo civil.

O crepúsculo civil é o estágio quando existe iluminância suficiente para habilitar atividades civis externas sem o uso de iluminação pública artificial. O crepúsculo civil termina ao fim da tarde e antes do início da manhã, quando o centro do Sol atinge uma distância zenital de $96^{\circ}$ (ou altura solar de $-6^{\circ}$ ). Para esse tipo de crepúsculo, a luminosidade varia de 700 lux a 3 lux. À medida em que se aproxima desse horário, o conforto visual sem iluminação artificial torna-se bastante degradado (MUNEER, 2004). No entanto, é preciso considerar que a altura solar de $-6^{\circ}$, estabelecida para o crepúsculo civil, não é fixa para todas as localidades da Terra, uma vez que esta é influenciada pela altitude, condições climáticas locais e tipo de céu.

Assim, pode-se notar que o crepúsculo de importância para a iluminação pública é o crepúsculo civil, o qual irá definir o momento em que a luz natural não é mais suficiente, devendo haver o acionamento da iluminação artificial.

\section{Acionamento de relés para iluminação pública}

No Brasil o acendimento e o desligamento do relé fotoelétrico são regulamentos pela NBR 5123 (ABNT, 1997). Os níveis estabelecidos para o acionamento e o desligamento do relé estão apresentados na Tabela 1. Pode-se, então, inferir o tempo mínimo e máximo de funcionamento de

42 Ferreira, C. C.; Souza, R. V. G. 
iluminação pública noturna, tomando como referência os níveis de iluminamento estabelecidos pela norma para o acionamento/desligamento da iluminação através dos relés.

\section{Modelos de iluminância externa}

\section{Determinação teórica da iluminância global}

Um dos poucos modelos para predição da iluminância global que contempla o período crepuscular foi desenvolvido por Seidelman (2006). O autor desenvolveu um modelo teórico para estimar os valores de iluminância, de acordo com a variação horária, para a condição de céu claro, englobando o período em que o sol encontra-se abaixo e acima da linha do horizonte. A iluminância $(\mathrm{E})$, em lux ou lumens por metro quadrado, é dada por (Eq. 1):

$\log 10 \mathrm{E}=\mathrm{I} 0+\mathrm{I} 1 \mathrm{x}+\mathrm{I} 2 \mathrm{x}^{2}+\mathrm{I} 3 \mathrm{x}^{3}$

Eq. 1

Onde:

$\mathrm{x}=\alpha_{\mathrm{s}} / 90$, sendo $\alpha_{\mathrm{s}}$ a altura solar; e

$\mathrm{I}_{0}, \mathrm{I}_{1}, \mathrm{I}_{2}$ e $\mathrm{I}_{3}$ são coeficientes tabulados para faixas de valores variáveis de altura solar, como mostra a Tabela 2.

Aplicando-se as fórmulas às alturas solares correspondentes, é possível construir um gráfico de iluminância pela altura solar, estipulando, assim, os valores de iluminância. Esses valores fornecem a iluminância direta e indireta da luz solar para dias de céu claro. A Figura 1 mostra o gráfico da curva teórica gerada a partir das equações para a cidade de Belo Horizonte (MG), Brasil, latitude $20^{\circ}$ sul.

A limitação deste modelo encontra-se no fato de ser aplicável apenas para a condição de céu claro.

\section{Software Helios}

Em 2006 teve início o Projeto de Pesquisa e Desenvolvimento CEMIG/ANEEL P\&D 128, intitulado de "Estudo da Disponibilidade de Luz Natural em Belo Horizonte como Base para Programação da Iluminação Pública Artificial Noturna", fruto de um convênio entre a Cemig, a Pontifícia Universidade Católica de Minas Gerais (PUC-Minas), através do Grupo de Estudos em Energia (Green Solar), e a Universidade Federal de Minas Gerais (UFMG), representada pelo Laboratório de Conforto Ambiental e Eficiência Energética (Labcon).

O P\&D 128 teve como produtos os modelos a serem apresentados no presente trabalho e o software Hélios, desenvolvido pela equipe da PUC-Minas, um modelo computacional para a estimativa dos níveis de iluminância do céu e cálculo da duração do dia, com base no cálculo geométrico da iluminância solar (valor teórico) ajustado pela pluviosidade (valor experimental). A partir das informações de localização geográfica do local (latitude e longitude) e da pluviosidade média mensal, o programa é apto a calcular a duração do dia para esse dado local (PEREIRA et al., 2009).

Tabela 1 - Valores de nível de iluminamento para acionamento dos relés fotoelétricos da iluminação pública

Fonte: NBR 5123 (ABNT, 1997).

\begin{tabular}{l|c|c}
\hline & $\begin{array}{c}\text { Amanhecer } \\
(\mathbf{l u x})\end{array}$ & $\begin{array}{c}\text { Anoitecer } \\
(\mathbf{l u x})\end{array}$ \\
\hline Caso 1 (tempo mínimo) & 80 & 20 \\
Caso 2 (tempo máximo) & 80 & 3 \\
\hline
\end{tabular}

Tabela 2 - Coeficientes para cálculo da iluminância da luz solar

\begin{tabular}{c|c|c|c|c|c|c}
\hline \multirow{2}{*}{ Intervalo de $\boldsymbol{\alpha}_{\mathbf{s}}$} & \multicolumn{5}{|c|}{ Coeficientes } & \multirow{2}{*}{ Erro máximo } \\
\cline { 2 - 6 } & $\mathrm{I}_{0}$ & $\mathrm{I}_{1}$ & $\mathrm{I}_{2}$ & $\mathrm{I}_{3}$ & 0,02 \\
\hline $20^{\mathbf{o}}$ & $90^{\mathbf{o}}$ & 3,74 & 3,97 & $-4,07$ & 1,47 & 0,02 \\
$5^{\mathbf{0}}$ & $20^{\mathbf{o}}$ & 3,05 & 13,28 & $-45,98$ & 64,33 & 0,02 \\
$-0,8^{\mathbf{o}}$ & $5^{\mathbf{o}}$ & 2,88 & 22,96 & $-207,64$ & 1034,30 & 0,02 \\
$-5^{\mathbf{o}}$ & $-0,8^{\mathbf{o}}$ & 2,88 & 21,81 & $-258,11$ & $-858,36$ & 0,01 \\
$-12^{\mathbf{o}}$ & $-5^{\circ}$ & 2,70 & 12,17 & $-431,69$ & $-1899,83$ & 0,01 \\
$-18^{\mathbf{o}}$ & $-12^{\mathbf{o}}$ & 13,84 & 262,72 & 1447,42 & 2797,93 & \\
\hline
\end{tabular}

Fonte: adaptado de Seidelman (2006). 
Figura 1 - Curva teórica de iluminância para Belo Horizonte (latitude 20²)

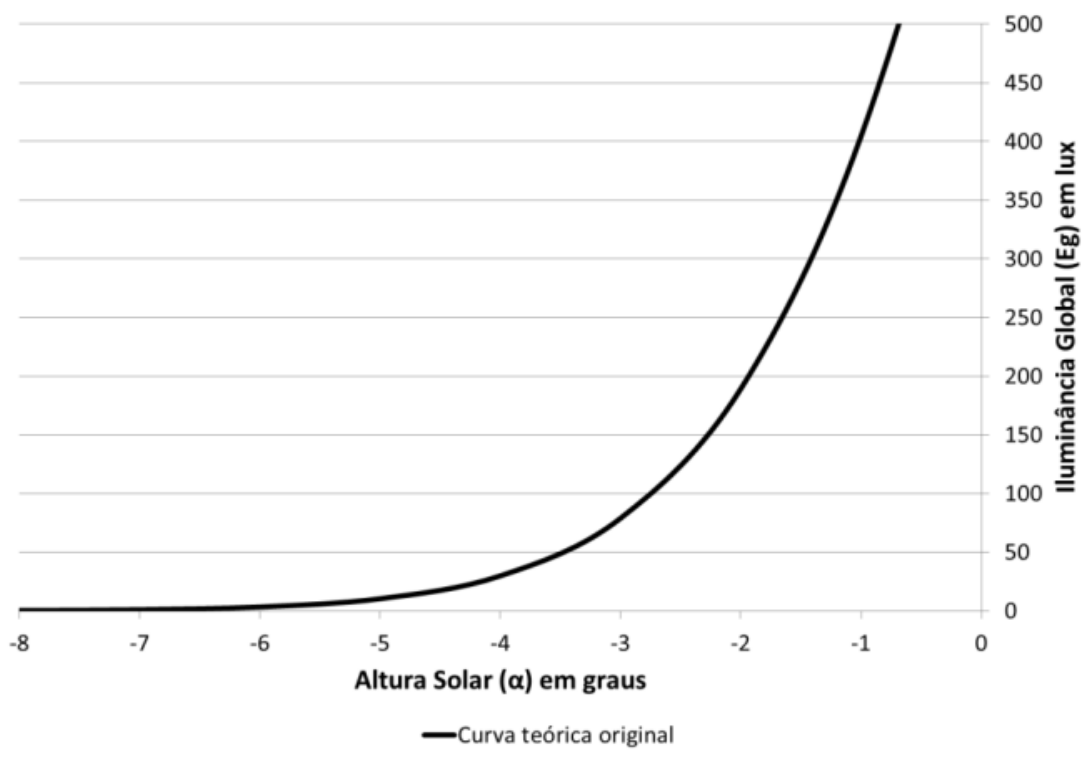

Os modelos de regressão apresentados no presente trabalho foram desenvolvidos paralelamente ao software, com o intuito de verificar especificamente a influência do tipo de céu na disponibilidade de luz natural. Acreditava-se que o tipo de céu poderia oferecer maior precisão do que a pluviosidade média local para a estimativa da iluminância externa, uma vez que a pluviosidade apresenta-se como uma variável discreta. Isso significa que podem ocorrer dias sem chuvas, mas de céu encoberto, quando há uma disponibilidade de luz natural menor.

\section{Metodologia}

Para que a duração da noite fosse estimada, foram desenvolvidos modelos de regressão a partir de dados medidos por uma estação padrão do Internacional Daylighting Measurement Programme da Comission Internationale de L'Eclaraige (CIE) (INTERNATIONAL..., 2008). Como estudo de caso, adotou-se a cidade de Belo Horizonte, Minas Gerais, Brasil, onde está localizada a estação de medição dos dados de iluminância para o período crepuscular.

A duração da noite é determinada por meio do intervalo estabelecido pela NBR 5123 (ABNT, 1997) para o acionamento a 20 lux e o desligamento a 80 lux, período no qual há a necessidade de acionamento da iluminação pública artificial.

Os dados foram organizados por tipo de céu em planilhas eletrônicas e tratados estatisticamente para a identificação e exclusão de dados espúrios, não representativos do conjunto de dados.
As medições foram realizadas na hora local. No entanto, para efeito de cálculo, o tratamento de dados deve ser realizado usando-se a hora solar. Há, porém, uma divergência entre a hora local e a hora solar. Essa diferença é decorrente do dia do ano e da longitude local. É então necessário aplicar correções aos dados medidos previamente ao início do tratamento efetivo dos dados. As correções aplicadas referem-se às diferenças devidas à longitude local, ao dia do ano, às alterações dos horários do computador, ao horário de verão e ao desgaste sofrido pelos sensores utilizados durante o período de medição.

Os modelos de disponibilidade de luz natural durante o crepúsculo foram desenvolvidos no presente trabalho para a predição de iluminâncias de céu. Estes foram obtidos a partir de regressões múltiplas no programa Excel ${ }^{\circledR}$ 2007. O objetivo da análise de regressão é avaliar as relações de dependência, as quais são capazes de explicar o comportamento de uma variável dependente a partir do comportamento de uma ou mais variáveis independentes. O nível de confiança adotado para todos os modelos é de $95 \%$.

Os modelos foram elaborados considerando-se cada condição de céu, as variáveis altura solar e as variáveis ajustadas $\alpha^{2}, \alpha^{3}, \alpha^{4}, \alpha^{5}$, investigando a melhor descrição do comportamento da luz natural no período crepuscular, diante das variações das condições externas de luminosidade.

O desempenho dos modelos foi testado perante a totalidade de dados, englobando todos os tipos de céu em um único modelo, e especificamente para cada um dos tipos de céu já abordados e descritos previamente: céu claro, céu intermediário e céu 
encoberto. É de relevância a separação por tipo de céu, uma vez que a presença de nuvens na abóbada celeste ocasiona a redução dos níveis de iluminância em razão da absorção e espalhamento da luz por elas.

A adequabilidade do modelo foi testada através da qualidade do ajustamento utilizando-se os índices de desempenho, o teste $F$ de significância conjunta dos parâmetros e da representatividade da curva de tendência em relação à nuvem de pontos medidos $\mathrm{e}$ por indicadores de desempenho $\left(\mathrm{r}^{2}{ }^{1}, \mathrm{MBD}^{2} \mathrm{e}\right.$ $\mathrm{RMSD}^{3}$ ).

A partir dos modelos desenvolvidos para cada tipo de céu, identificaram-se os níveis de acendimento (20 lux) e desligamento (80 lux) da iluminação pública artificial, sua respectiva altura solar e, consequentemente, seu horário de ocorrência, determinando, assim, a duração da noite.

\section{Estação de medição de iluminação natural (EMIN-BH)}

\section{Localização}

A cidade de Belo Horizonte está delimitada pelas latitudes $19^{\circ} 46^{\prime}$ e $20^{\circ} 03^{\prime}$ sul e pelas longitudes $43^{\circ} 51^{\prime}$ e $44^{\circ} 03^{\prime}$ ' oeste.

Os dados medidos utilizados no presente trabalho foram coletados na Estação de Medição de Iluminação Natural de Belo Horizonte (EMINBH). A EMIN-BH caracteriza-se como uma estação de Classe Geral, de acordo com o padrão IDMP (INTERNATIONAL..., 2008), coletando dados de iluminância global horizontal, iluminância difusa horizontal, irradiância difusa horizontal e iluminâncias verticais nas direções norte, sul, leste e oeste.

A EMIN-BH está fixada na cidade de Belo Horizonte, no prédio do Centro Brasileiro para o Desenvolvimento em Energia Solar Térmica (Green Solar), no campus da Pontifícia Universidade Católica de Minas Gerais, PUC-MG, região noroeste da cidade.

\footnotetext{
${ }^{1}$ Representa a porcentagem da variação total de Eg, que pode ser explicada pela equação de regressão.

${ }^{2} \mathrm{O}$ desvio médio MBD indica a tendência do modelo à subestimação (valores de MBD negativos) ou à superestimação (valores de MBD positivos).

${ }^{3} \mathrm{O}$ desvio quadrático médio (RMSD) é uma medida de desvio dos valores preditos pelos modelos em relação aos valores medidos, dada em porcentagem. O RMSD deve conter sempre um valor positivo e, quanto mais próximo de zero, maior a precisão do modelo.
}

\section{Dados coletados}

Os dados medidos pela EMIN-BH podem ser divididos em dois grupos: dados de dia inteiro e dados crepusculares. Não há diferença no modo como as medições foram realizadas, mas nas faixas de medição, uma vez que no período crepuscular a intensidade luminosa é bastante inferior aos outros períodos do dia, assim os mesmos sensores não podem ser utilizados em ambos os períodos por esse motivo. Os dados de iluminância global neste período foram medidos por um sensor específico para faixas mais baixas (de 0 lux a aproximadamente 400 lux, não ultrapassando os 1.000 lux). Os dados foram coletados pelo período de agosto de 2007 a novembro de 2008, em intervalos de $1 \mathrm{~min}$.

A avaliação da qualidade metrológica dos dados de iluminância medidos durante o crepúsculo local pela EMIN-BH foi realizada por Arreguy (2008). Segundo a autora, o valor da incerteza estimado foi da ordem de $10 \%$ do valor medido, significando um impacto máximo em relação aos horários de ocorrência dos valores de iluminância de interesse (20 lux e 80 lux) de 2 min, ocasionando, dessa forma, uma variação máxima provável de $4 \mathrm{~min}$ ao longo do dia.

\section{Tratamento dos dados coletados}

Por meio de planilha eletrônica, os dados foram organizados para corresponder ao respectivo dia Juliano, com a hora no formato "hora:minuto" convertida em minutos. Além disso, para efeito de cálculo, converteu-se a hora civil em hora solar verdadeira, aplicando as devidas correções referentes à longitude e a equação do tempo em virtude da existência de uma divergência entre a hora local e a hora solar.

A correção da longitude é dada pela Equação 2, a seguir (DUFFIE; BECKMAN, 2006).

$\mathrm{X}=\mathrm{h}\left(\lambda_{\mathrm{s}}-\lambda_{\mathrm{e}}\right)$

Eq. 2

Onde:

$\mathrm{X}$ é a correção da longitude, expressa em minutos;

$\lambda s$ é a longitude padrão; e

$\lambda$ e é a longitude local.

A diferença entre a hora padrão e a hora solar é definida pela Equação da Hora $\left(E_{t}\right)$, que pode ser obtida através da Equação 3 e 4 (DUFFIE; BECKMAN, 2006):

$E_{t}=(0,00075+0,001868 \cos x-0,032077 \operatorname{sen} x-$ $\left.0,014615 \cos ^{2} x-0,04089 \operatorname{sen}^{2} x\right) *(229,18) \quad$ Eq. 3

$x=\frac{60 *(J-1)}{365}$

Eq. 4 
Onde:

$\mathrm{E}_{\mathrm{t}}$ é a Equação da Hora, expressa em minutos; e J é o dia Juliano.

A hora solar verdadeira é a hora determinada pela rotação da Terra relativamente ao Sol e é esta a hora que deve ser utilizada em qualquer cálculo de geometria solar.

Para encontrar a hora solar verdadeira, aplicou-se a Equação 5 (ABNT, 2005):

$\mathrm{h}_{\mathrm{s}}=\mathrm{HLP}+4 \times\left(\lambda_{\mathrm{s}}-\lambda_{\mathrm{e}}\right)+\mathrm{Et}$

Eq. 5

Onde:

$\mathrm{h}_{\mathrm{s}}$ é a hora solar verdadeira;

HLP é a hora local padrão;

$\lambda_{\mathrm{s}}$ é a longitude padrão;

$\lambda_{\mathrm{e}}$ é a longitude local; e

$\mathrm{E}_{\mathrm{t}}$ é a equação da hora.

Com os dados devidamente organizados e correspondentes à hora solar verdadeira e ao dia Juliano da medição, a altura solar correlata a cada medição foi calculada, de acordo com a Equação 6 (ABNT, 2005):

$\alpha_{\mathrm{s}}=\operatorname{arcsem}(\operatorname{sen} \varphi \operatorname{sen} \delta-\cos \varphi \cos \delta \cos \omega) \quad$ Eq. 6

Onde:

$\alpha$ s é a altura solar;

$\varphi$ é a latitude local;

$\delta$ é a declinação solar; e

$\omega$ é a hora angular.

\section{Caracterização dos tipos de céu}

A partir da organização dos dados, estes foram agrupados conforme o tipo de céu: céu claro, céu parcialmente encoberto (ou intermediário) e céu encoberto, seguindo a classificação explicitada na NBR 15215-2 (ABNT, 2005).

Em decorrência da inexistência de luz direta no período considerado, parâmetros climáticos para parametrização do tipo de céu não puderam ser adotados, sendo, por isso, adotada a classificação dos tipos de céu através de processo visual. Para a avaliação do tipo de céu, foram utilizadas fotos do céu obtidas por imageador da marca Yankee, instalado junto à EMIN-BH, coletadas a cada 5 min durante a alvorada e o ocaso. Por meio do registro das fotos, a proporção de recobrimento da abóbada celeste por nuvens foi visualmente analisada, e o tipo de céu designado.

\section{Caracterização dos tipos de céu mais frequentes em cada mês para dada localidade}

Ferreira e Souza (2006) desenvolveram um método simplificado para a definição do céu típico mensal para determinada localidade com base nos dados de horas de insolação mensal medidos em estações meteorológicas e nas equações de Duffie e Beckman (2006).

$\mathrm{O}$ valor médio mensal das horas de insolação pode ser obtido através da Equação 7 (FERREIRA; SOUZA, 2006):

$\mathrm{n}=\frac{\text { insolação mensal }}{\mathrm{n}^{\mathbf{o}} \text { de dias do mês }}$

Eq. 7

O valor calculado de $n$ é comparado ao número médio máximo de horas de insolação, $\mathrm{N}$, que se poderia ter sob condições de céu claro, fornecendo o percentual de cobertura de nuvens da abóbada celeste e, por conseguinte, o tipo de céu. $\mathrm{O}$ valor de $\mathrm{N}$ pode ser obtido a partir da Equação 8 (FERREIRA; SOUZA, 2006):

$\mathrm{N}=(2 / 15) \cos -1(-\tan \varphi \times \tan \delta)$

Eq. 8

Quando o número de horas de insolação, n, é inferior a $40 \%$ do total, N, o céu típico do período analisado é considerado encoberto; entre $40 \%$ e $70 \%$, o céu é parcialmente encoberto; e acima de $70 \%$, o céu é considerado claro (FERREIRA; SOUZA, 2006).

Com o intuito de identificar os tipos de céus típicos de cada mês do ano para a cidade de Belo Horizonte, foi aplicado o método simplificado desenvolvido por Ferreira e Souza (2006). Os dados de insolação mensal foram obtidos a partir das Normais Climatológicas de 1961-1990 (BRASIL, 1992). A classificação, conforme a Tabela 3, foi de céu predominante claro para os meses de junho, julho e agosto; janeiro, outubro, novembro e dezembro como meses de céu predominantemente encoberto; e fevereiro, março, abril, maio e setembro como meses de céu predominante parcialmente encoberto.

\section{Desenvolvimento}

Neste item são apresentados os modelos de iluminância global horizontal $\left(\mathrm{E}_{\mathrm{g}}\right)$, gerados a partir das regressões, para a determinação de luz natural no crepúsculo, assim como seus testes de desempenho. A partir dos modelos, calculou-se a duração da noite, e os valores obtidos foram comparados a valores medidos de agosto de 2007 a julho de 2008 pela EMIN-BH para a validação dos modelos. 
Tabela 3 - Tabela de classificação simplificada de condições de céus para Belo Horizonte

\begin{tabular}{c|c|c|c|c|c}
\hline Mês & In. mês & $\mathbf{n}$ & $\mathbf{N}$ & \% & Tipo de céu \\
\hline Janeiro & 189,8 & 6,12 & 13,10 & 46,74 & Encoberto \\
Fevereiro & 195,5 & 6,74 & 12,66 & 53,27 & Parc. encoberto \\
Março & 215,1 & 6,94 & 12,12 & 57,26 & Parc. encoberto \\
Abril & 228,9 & 7,63 & 11,54 & 66,12 & Parc. encoberto \\
Maio & 237,1 & 7,65 & 11,06 & 69,18 & Parc. encoberto \\
Junho & 240,1 & 8,00 & 10,82 & 74,01 & Claro \\
Julho & 256,5 & 8,27 & 10,93 & 75,68 & Claro \\
Agosto & 255,6 & 8,25 & 11,34 & 72,73 & Claro \\
Setembro & 210,1 & 7,00 & 11,91 & 58,79 & Parc. encoberto \\
Outubro & 190,5 & 6,15 & 12,49 & 49,21 & Encoberto \\
Novembro & 181,7 & 6,06 & 12,94 & 46,81 & Encoberto \\
Dezembro & 165,1 & 5,33 & 13,19 & 40,37 & Encoberto \\
\hline
\end{tabular}

A nuvem de pontos para a condição de céu claro apresenta-se menos dispersa, conforme esperado, por ser esta uma condição de céu mais estável em relação às outras condições de céu. É identificável, mesmo para esta condição de céu, a presença da dispersão decorrente das condições atmosféricas, que irá variar em função da quantidade de partículas e de vapor d'água na atmosfera, originando em desvios decrescentes em relação à média a partir da altura solar de $-4^{\circ}$. Em oposição, a nuvem de pontos para a condição de céu encoberto mostra-se a mais dispersa, ocorrendo a concentração de dados em dois extremos da curva da nuvem, provavelmente consequência da diferença de conteúdo de vapor de água existente na atmosfera nas duas situações.

Todos os modelos de regressão desenvolvidos no presente trabalho têm um limite de aplicação mínimo de $-6,0^{\circ}$ de altura solar, faixa esta que inclui o crepúsculo civil. Abaixo de tal valor, as curvas polinomiais tendem a flexionar-se de forma pouco representativa da realidade.

\section{Modelo para todos os tipos de céu}

$\mathrm{Na}$ Figura 2 está representado o gráfico de dispersão de iluminância global $\left(\mathrm{E}_{\mathrm{g}}\right)$ pela altura solar $\left(\alpha_{\mathrm{s}}\right)$ para todas as condições de céu. A linha preta pontilhada representa a curva teórica desenvolvida por Seidelman (2006) e, em cinza, a curva de tendência do modelo gerado. Nota-se na figura que o polinômio desenvolvido parece ter melhor aderência aos dados que a curva teórica.

A equação de regressão gerada para o modelo polinomial para todas as condições de céu está apresentada na Equação 9. Para a equação de regressão gerada, o valor de $\mathrm{r}^{2}$ é de 0,90 , mostrando ser o modelo explicativo do fenômeno de forma significativa. O MBD encontrado foi de 9,41, apontando valores subestimados pelo modelo, e um RMSD de $22,95 \%$.
$E_{g_{2}}=-0,0992 \alpha_{s}{ }^{5}-2,5858 \alpha_{s}{ }^{4}-23,214 \alpha_{s}{ }^{3}-73,367$ $\alpha_{\mathrm{s}}^{2}+33,712 \alpha_{\mathrm{s}}+412,59$

Apesar de o modelo ser explicativo e significativo, pode-se observar uma grande dispersão da nuvem de pontos medidos. Com isso, optou-se por agrupar os dados medidos de acordo com a condição de céu e gerar modelos de regressão para cada condição de céu específica, de forma a obterem-se modelos de maior representatividade do fenômeno.

\section{Modelo para a Condição de Céu Claro}

Na Figura 3 está representado o gráfico para a condição de céu claro, em preto a curva teórica e em cinza a curva de tendência do modelo gerado. Nela fica explícita a existência de uma semelhança de comportamento entre a curva de tendência do modelo polinomial e a curva teórica.

Encontrou-se para este modelo a Equação 10 e um valor de $\mathrm{r}^{2}$ elevado de 0,95 , mostrando que grande parte da iluminância global para a condição de céu claro pode ser explicada pela equação de regressão gerada. O MBD encontrado foi de 1,04, apontando uma pequena superestimação pelo modelo, e um RMSD de $16,10 \%$ :

$E_{g}=-0,4689 \alpha_{s}^{5}-9,8851 \alpha_{s}^{4}-76,622 \alpha_{s}^{3}-247,08 \alpha_{s}^{2}$ - $187,28 \alpha_{\mathrm{s}}+387,84$

Ao calcular-se a duração da noite com o uso desses modelos, há uma divergência entre o modelo teórico e o modelo polinomial para céu claro de aproximadamente 1,5 min, valor este pouco significativo, uma vez que há ainda que se considerar a incerteza da medição (em torno de 2 min) e a incerteza inerente ao próprio modelo. Em resumo, para a condição de céu claro, não há uma diferença significativa entre o modelo teórico e o proposto. 
Figura 2 - Gráfico de dispersão da iluminância global pela altura solar para todas as condições de céu

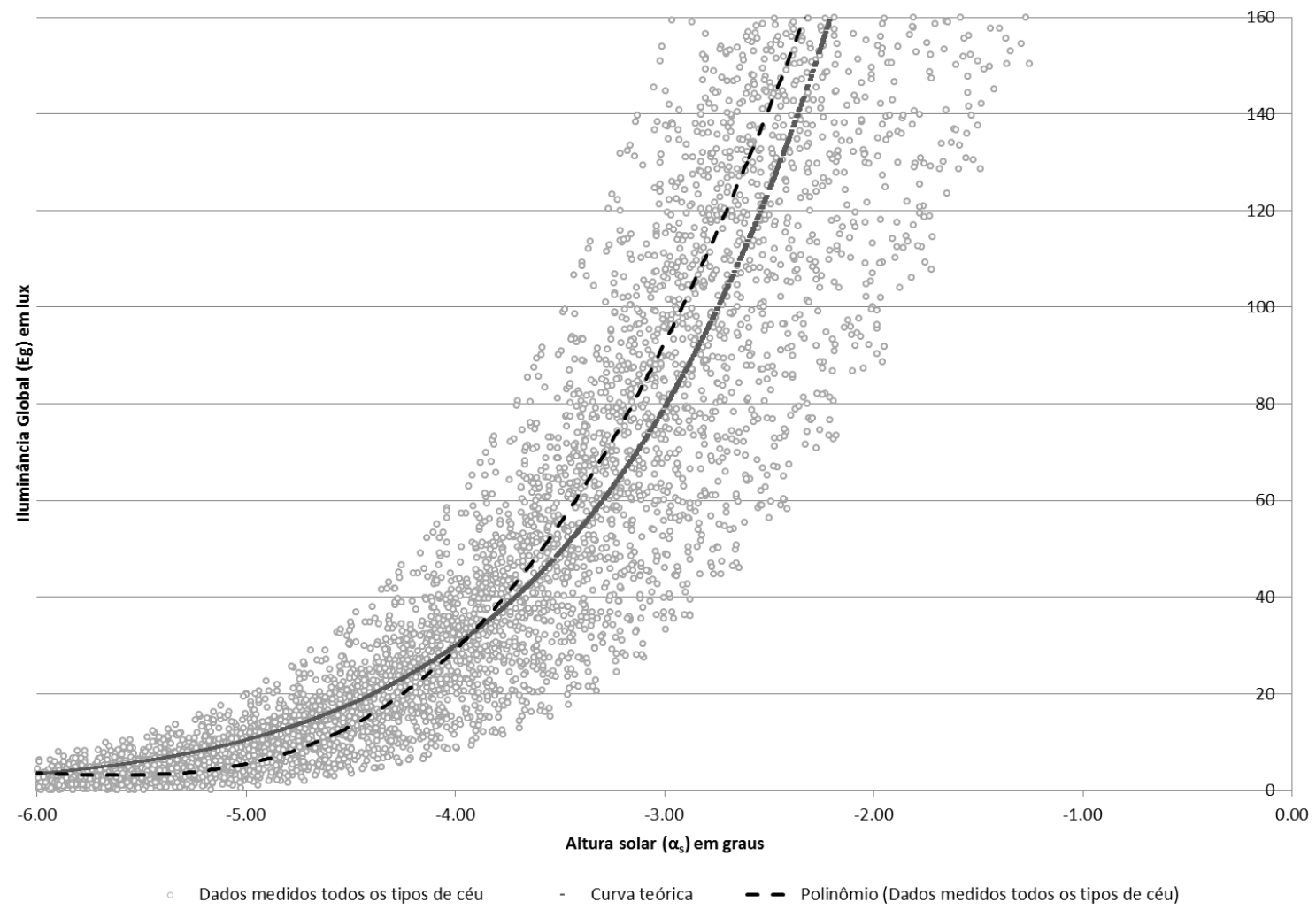

Figura 3 - Gráfico de dispersão da iluminância global pela altura solar para a condição de céu claro

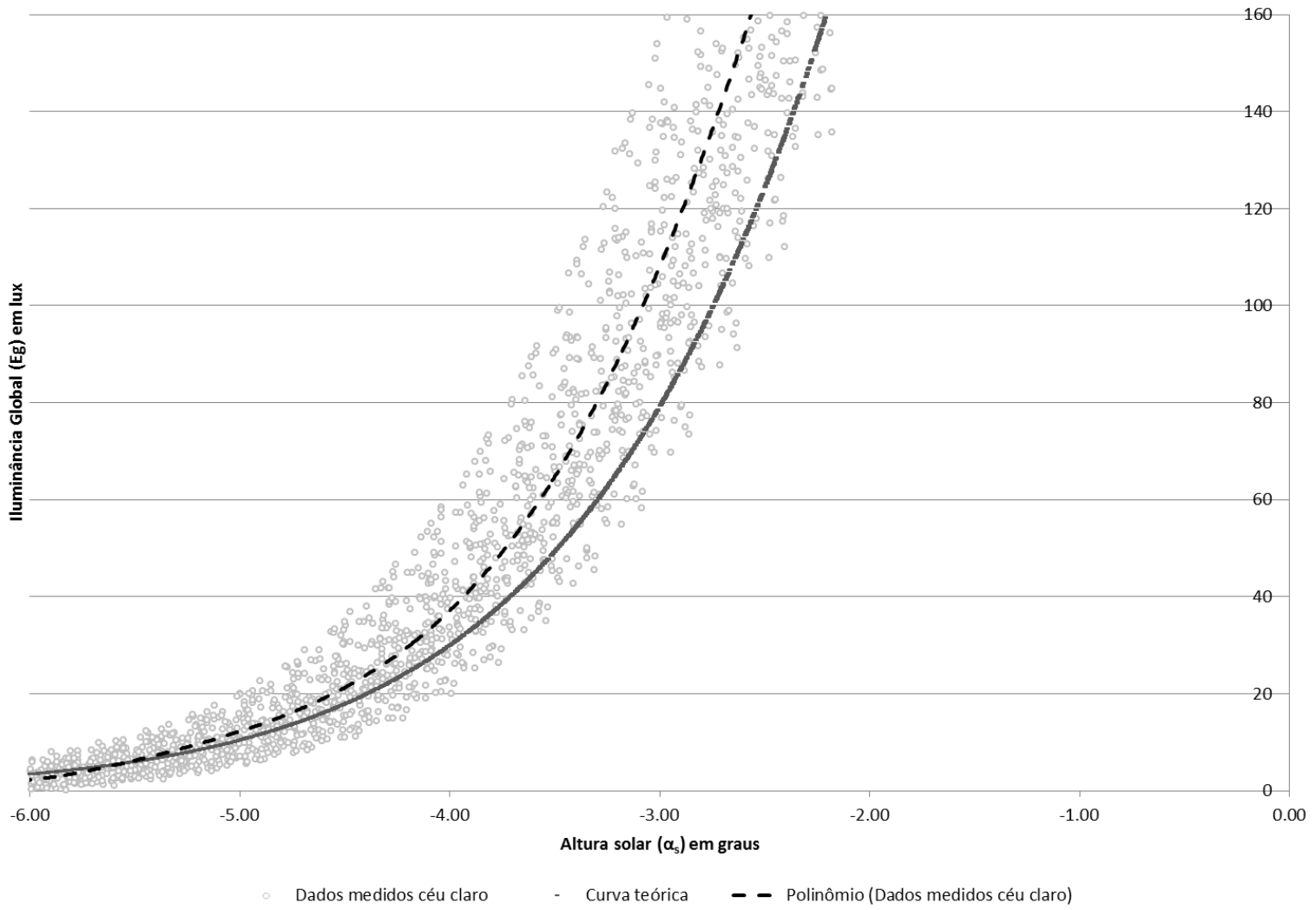

48 Ferreira, C. C.; Souza, R. V. G. 


\section{Modelo para a condição de céu parcialmente encoberto}

Na Figura 4 está representado o gráfico com a nuvem de pontos medidos para a condição de céu parcialmente encoberto, assim como sua respectiva curva de tendência (em cinza) e a curva do modelo teórico (em preto). A equação gerada é apresentada na Equação 11:

$E_{g}=-0,0945 \alpha_{s}^{5}-2,4603 \alpha_{s}^{4}-21,319 \alpha_{s}^{3}-60,593 \alpha_{s}^{2}$ $+63,603 \alpha_{\mathrm{s}}+415,88$

Eq. 11

Para o modelo de regressão para a condição de céu parcialmente encoberto foi verificado um $r^{2}$ de 0,92, o que demonstra ser o modelo explicativo para esta condição de céu.

Apesar de o modelo desenvolvido ter-se mostrado representativo, pode-se observar que sua curva de tendência apresenta uma flexão às baixas alturas solares $\left(\alpha \leq-6^{\circ}\right)$, não correspondentes ao real comportamento da curva formada pela nuvem de pontos. Devido à inexistência de um modelo teórico específico para esse tipo de céu, comparouse a curva do modelo com a curva do modelo de Seidelman (2006) (curva teórica) e observou-se que a curva do modelo proposto possui a flexão que melhor representa os dados medidos.

Propôs-se, então, dividir o modelo de céu parcialmente encoberto, aqui proposto, em faixas, assim como é feito no modelo proposto por Seidelman (2006), que é dividido em faixas de altura solar, e para estas são geradas diferentes equações de mesmo grau de polinômio.

Os limites das faixas são estabelecidos a partir do ponto de interseção entre as duas equações ou aquele que mais se aproxima deste ponto, ou seja, $\mathrm{y}_{1}-\mathrm{y}_{2}=0$. No ponto de interseção, as inclinações das curvas de tendência de $y_{1}$ e $y_{2}$ devem ser equivalentes. Matematicamente, esta condição é satisfeita se as derivadas das funções forem iguais no ponto de interseção, que é encontrado por tentativas. A partir da diferença na posição das duas curvas originais $\left(\mathrm{y}_{1}-\mathrm{y}_{2}\right)$, pode-se, então, modificar o último termo do polinômio de cada curva na metade desta diferença ou apenas uma das curvas no valor total da diferença, uma vez que as derivadas não se alteram, já que o último termo delas não é função de $\mathrm{x}$. Ao final, o valor de $\mathrm{r}^{2}$ é recalculado com o objetivo de verificar se este não foi sensivelmente alterado.

Figura 4 - Gráfico de dispersão para a condição de céu parcialmente encoberto

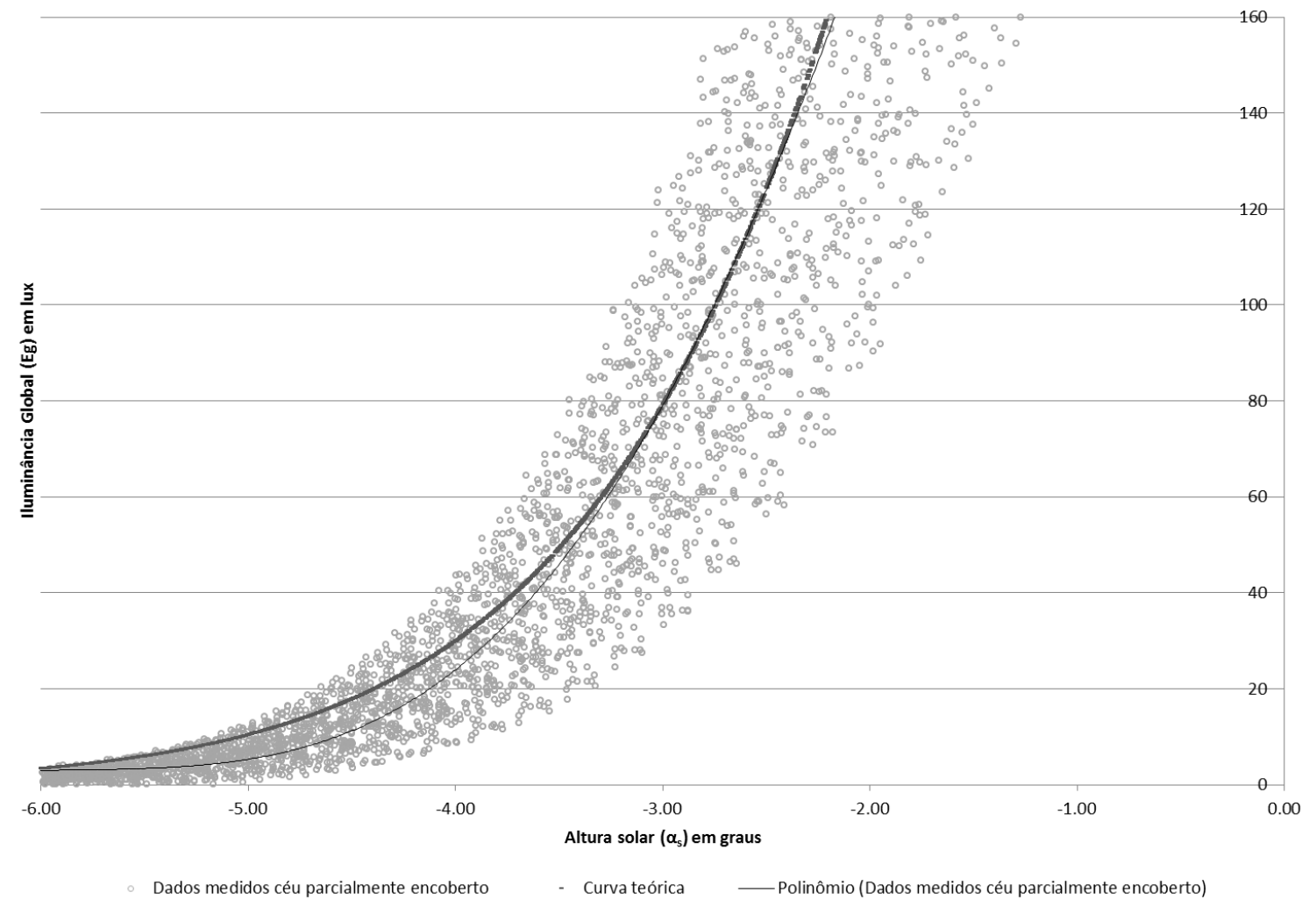


Para o modelo de céu parcialmente encoberto, os dados foram divididos em duas faixas, de acordo com o ponto de interseção das curvas de tendências dos modelos, sendo $\mathrm{y}_{1}-\mathrm{y}_{2}=0,0$ para este ponto:

(a) dados com $\alpha_{\mathrm{s}}$ menor que $-3,866^{\circ}$; e

(b) dados com $\alpha_{\mathrm{s}}$ maior ou igual a $-3,866^{\circ}$.

Encontrou-se para estas duas faixas os seguintes resultados:

(a) para a faixa $1, \mathrm{r}^{2}=0,81$;

(b) para a faixa $2, \mathrm{r}^{2}=0,89$.

Gerando a derivada para as equações de cada uma das faixas (Tabela 4), obteve-se o apresentado na Tabela 4.

A partir dessa nuvem de pontos, um novo modelo foi gerado, conforme a Tabela 5 .

O modelo unificado para a condição de céu parcialmente encoberto apresentou um $\mathrm{r}^{2}$ bastante alto $(0,94)$, mostrando-se explicativo, valor este pouco superior ao $\mathrm{r}^{2}$ de 0,92 encontrado para o modelo único. O MBD encontrado foi de $-1,91$, apontando valores levemente subestimados pelo modelo, e um RMSD de 19,04\%.

\section{Modelo para a condição de céu encoberto}

O gráfico da Figura 5 mostra haver uma grande divergência da curva de tendência do modelo de regressão para a condição de céu encoberto (em cinza) para a curva teórica (em preto), gerada para a condição de céu claro, apontando ser a curva gerada para céu claro (SEIDELMAN, 2006), pouco representativa dessa condição para a cidade de Belo Horizonte.

A equação gerada está descrita na Equação 12.

$\mathrm{E}_{\mathrm{g}}=-0,0473 \alpha_{\mathrm{s}}{ }^{5}-0,9432 \alpha_{\mathrm{s}}{ }^{4}-5,3759 \alpha_{\mathrm{s}}{ }^{3}+3,496 \alpha_{\mathrm{s}}{ }^{2}$ $+115,32 \alpha_{\mathrm{s}}+262,52 \quad$ Eq. 12

Assim como no caso do modelo de regressão para a condição de céu parcialmente encoberto, optouse por dividir o modelo de regressão para a condição de céu encoberto em faixas.

Para o modelo de céu encoberto, os dados foram divididos em duas faixas, de acordo com o ponto de interseção das curvas de tendências dos modelos, sendo $\mathrm{y}_{1}-\mathrm{y}_{2}=-0,0$ para este ponto:

(a) dados com $\alpha$ s menor que $-2,181^{\circ}$; e

(b) dados com $\alpha$ s maior ou igual a $-2,181^{\circ}$.

Encontrou-se para estas duas faixas as equações dispostas na Tabela 6.

Gerando a derivada para as equações de cada uma das faixas obteve-se o conteúdo da Tabela 7.

Tabela 4 - Derivadas das equações do modelo por faixas para céu parcialmente encoberto

\begin{tabular}{c|c|c}
\hline Faixa & Derivada no ponto de interseção & $\begin{array}{c}\text { Diferença entre } \\
\text { os ângulos* }\end{array}$ \\
\hline Faixa 1 & $5 * 0,0947 \alpha_{s} 4+4 * 3,0448 \alpha_{s} 3+3 * 39,558 \alpha_{s} 2+2 * 260,87 \alpha_{s}+877,65$ & \multirow{2}{*}{$-0,011$} \\
\hline Faixa 2 & $5 * 0,6076 \alpha_{s} 4+4 * 5,8292 \alpha_{s} 3+3 * 11,799 \alpha_{s} 2-2 * 11,066 \alpha_{s}+80,568$ & \\
\hline
\end{tabular}

Nota: *ângulos entre as duas curvas de tendência referentes a cada uma das faixas de dados por altura solar $\left(\mathrm{a}_{\mathrm{s}}\right)$.

Tabela 5 - Equação final para a condição de céu parcialmente encoberto e seu respectivo $r^{2}$

\begin{tabular}{c|c}
\hline Equação & $\mathbf{r}^{2}$ \\
\hline $\mathrm{Eg}=-0,1328 \times 5-3,1322 \times 4-25,653 \times 3-72,701 \times 2+52,49 \mathrm{x}+421,17$ & 0,94 \\
\hline
\end{tabular}

50 Ferreira, C. C.; Souza, R. V. G. 
Figura 5 - Gráfico de dispersão para a condição de céu encoberto, com modelos de Seidelman e curva de regressão polinomial

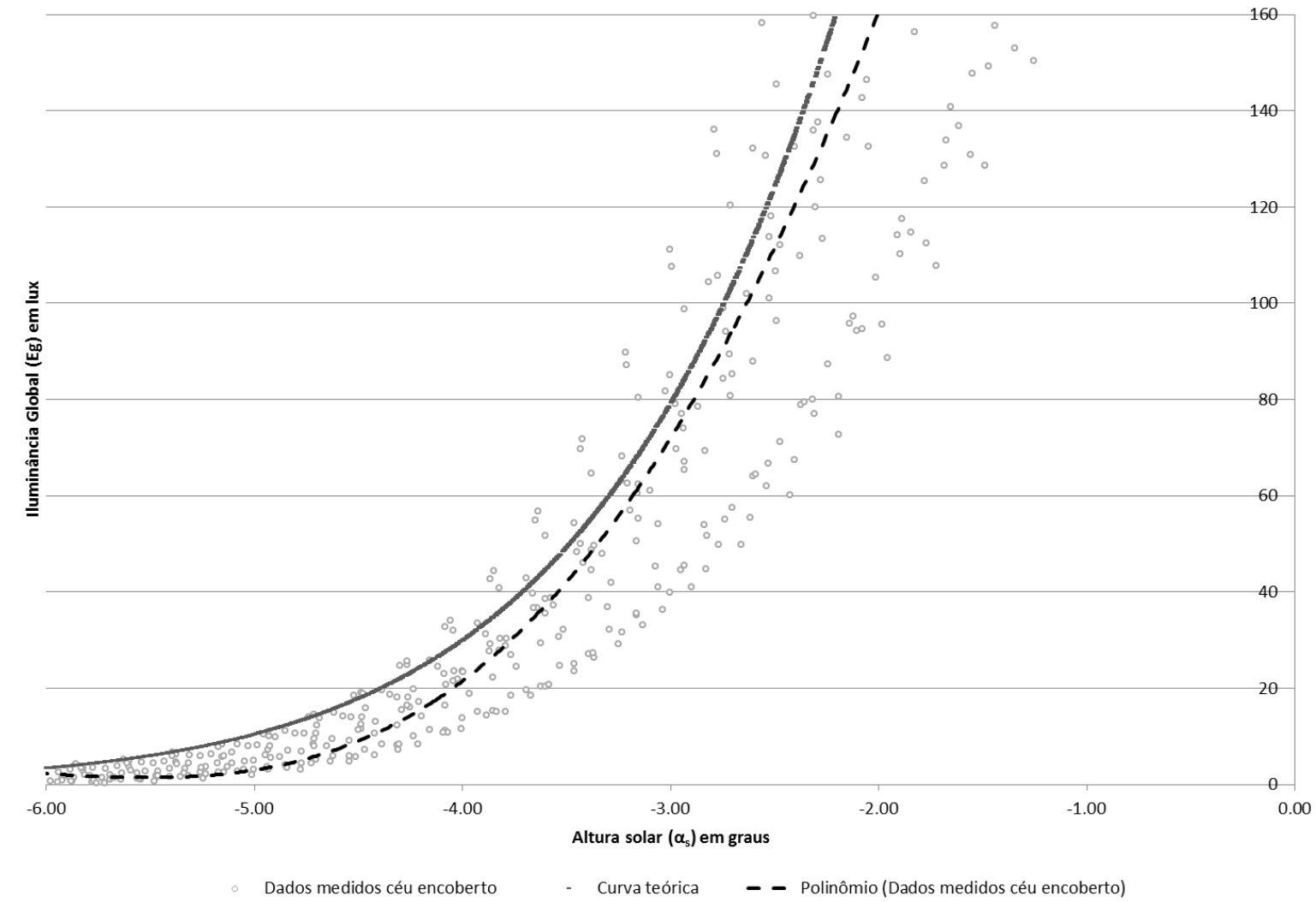

Tabela 6 - Equações das faixas de dados de céu encoberto

\begin{tabular}{l|c|c}
\hline & Equação & $\mathbf{r}^{2}$ \\
\hline Faixa 1 & $\mathrm{Eg}=-0,0007 \times 5+0,0886 \times 4+2,7625 \times 3+29,577 \times 2+138,07 x+241,63$ & 0,87 \\
Faixa 2 & $\mathrm{Eg}=0,3155 \times 5+0,4616 \times 4-7,5005 \times 3-3,733 \times 2+119,09 x+258,8$ & 0,88 \\
\hline
\end{tabular}

Tabela 7 - Derivadas das equações do modelo por faixas para céu encoberto

\begin{tabular}{c|c|c}
\hline Faixa & Derivada no ponto de interseção & $\begin{array}{c}\text { Diferença entre o } \\
\text { ângulo }\end{array}$ \\
\hline Faixa 1 & $5 * 0,3155 \alpha_{\mathrm{s}}{ }^{4}+4 * 0,4616 \alpha_{\mathrm{s}}{ }^{3}-3 * 7,5005 \alpha_{\mathrm{s}}{ }^{2}-2 * 3,733 \alpha_{\mathrm{s}}+119,09$ & \multirow{2}{*}{$-0,002$} \\
\hline Faixa 2 & $5 * 0,0007 \alpha_{\mathrm{s}}{ }^{4}+4 * 0,0886 \alpha_{\mathrm{s}}{ }^{3}+3 * 2,7625 \alpha_{\mathrm{s}}{ }^{2}+2 * 29,577 \alpha_{\mathrm{s}}+138,07$ & \\
\hline
\end{tabular}

Foi, então, modificado apenas o último termo do polinômio da equação da segunda faixa $\left(\mathrm{y}_{2}\right)$ pela diferença total encontrada, pelo fato de a curva da primeira faixa apresentar um bom comportamento. A partir dessas duas equações, calcularam-se os valores de $\mathrm{E}_{\mathrm{g}}$, gerando uma nova nuvem de pontos, denominada Modelo por faixas de céu encoberto, encontrando-se o gráfico representado na Figura 6, estando representada em cinza a curva de tendência.
A partir dessa nuvem de pontos, um novo modelo foi gerado, conforme a Tabela 8 .

O modelo unificado para a condição de céu encoberto apresentou um $\mathrm{r}^{2}$ alto $(0,91)$, mostrandose explicativo. O MBD encontrado foi de $-1,39$, apontando valores levemente subestimados pelo modelo, e um RMSD de 25,44\%. 
Figura 6 - Gráfico de dispersão com o modelo reunificado a partir das faixas para a condição de céu encoberto

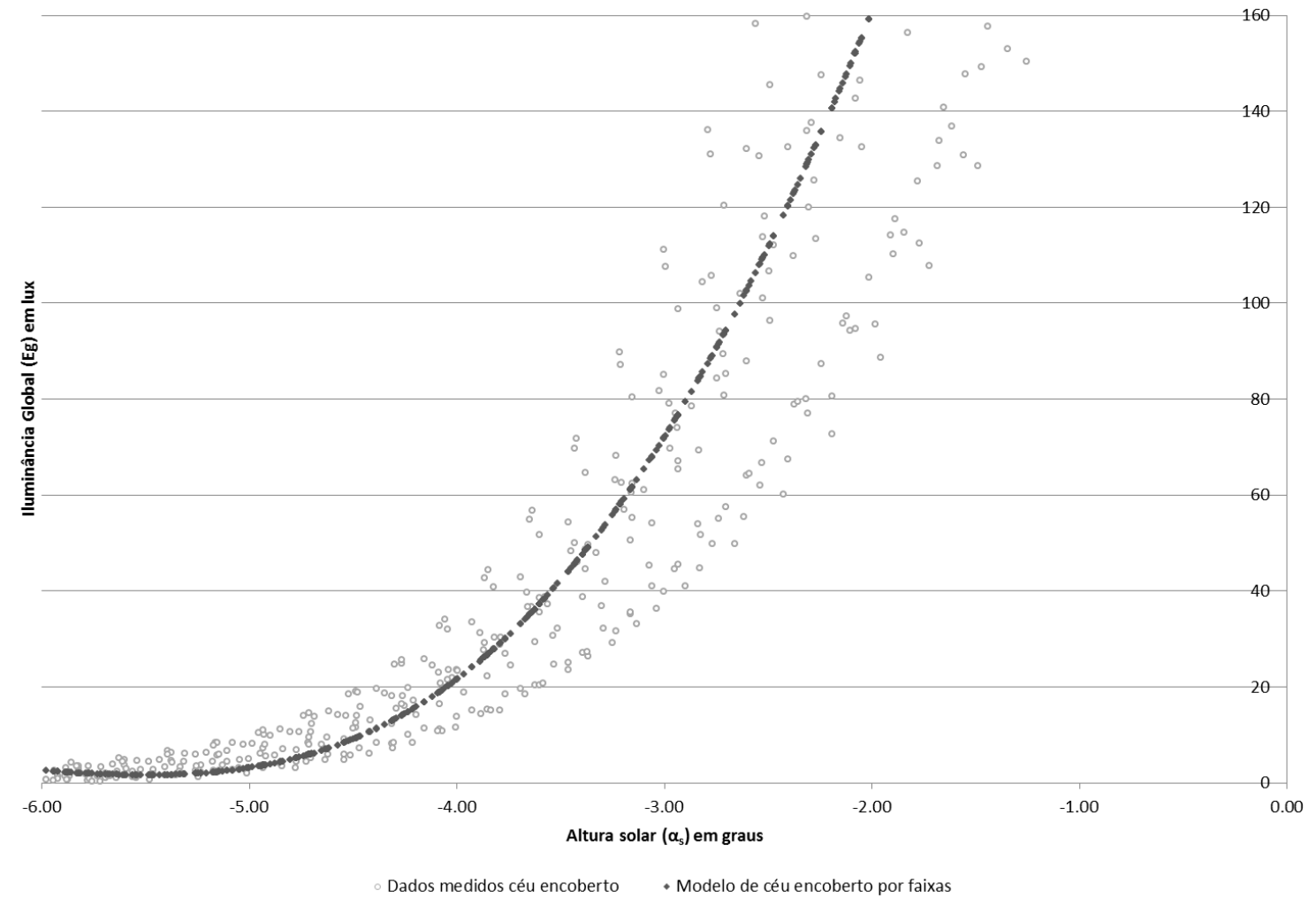

Tabela 8 - Equação final para o modelo para a condição de céu encoberto e seu respectivo $r^{2}$

\begin{tabular}{c|c}
\hline Equação & $\mathbf{r}^{2}$ \\
\hline $\mathrm{Eg}=-0,0007 \mathrm{x}^{5}+0,0886 \mathrm{x}^{4}+2,7625 \mathrm{x}^{3}+29,577 \mathrm{x}^{2}+138,07 \mathrm{x}+241,63$ & 0,91 \\
\hline
\end{tabular}

\section{Resumo dos modelos de regressão}

Em resumo, os modelos gerados para as curvas polinomiais ao final de todo o processo estão apresentados na Tabela 9 e 10. A partir da classificação dos tipos de céus típicos em cada mês para a cidade de Belo Horizonte, segundo o método desenvolvido por Ferreira e Souza (2006), aplicaram-se os modelos desenvolvidos para cada tipo de céu aos respectivos tipos de céu típicos para cada mês do ano, estimando-se os horários diários de ocorrência dos valores fixados de iluminância e calculando-se a duração da noite (em horas) média mensal e anual para aquela cidade.

Os valores médios encontrados pelos modelos foram confrontados com os valores médios medidos, bem como com os valores extraídos da curva teórica apresentada por Seidelman (2006), aqui denominado modelo teórico. Os valores referentes à curva teórica fazem menção a dias de céu claro, podendo seus valores ser comparados apenas aos meses em que a condição típica é a de céu claro. Os valores obtidos são apresentados na Tabela 10.

A curva cinza-claro representa o modelo de céu claro, a curva em cinza intermediário, o modelo de céu parcialmente encoberto, e a linha cinza-escuro, o modelo de céu encoberto. Em preto está a curva teórica.

\section{Cálculo da duração da noite em função dos modelos e tipos de céu para fins de acendimento e desligamento de iluminação pública}

Para o cálculo da duração da noite, empregaram-se como critérios balizadores os níveis de iluminação propostos pela norma NBR 5123 (ABNT, 1997), tendo seu início definido como 20 lux e seu término ao nível de 80 lux.

A partir da classificação dos tipos de céus típicos em cada mês para a cidade de Belo Horizonte, segundo o método desenvolvido por Ferreira e Souza (2006), aplicaram-se os modelos 
desenvolvidos para cada tipo de céu aos respectivos tipos de céu típicos para cada mês do ano, estimando-se os horários diários de ocorrência dos valores fixados de iluminância e calculando-se a duração da noite (em horas) média mensal e anual para aquela cidade.

Os valores médios encontrados pelos modelos foram confrontados com os valores médios medidos, bem como com os valores extraídos da curva teórica apresentada por Seidelman (2006), aqui denominado modelo teórico. Os valores referentes à curva teórica fazem menção a dias de céu claro, podendo seus valores ser comparados apenas aos meses em que a condição típica é a de céu claro. Os valores obtidos são apresentados na Tabela 10.

Figura 7 - Gráfico representando as curvas de tendência dos modelos polinomiais para cada condição de céu e a curva teórica

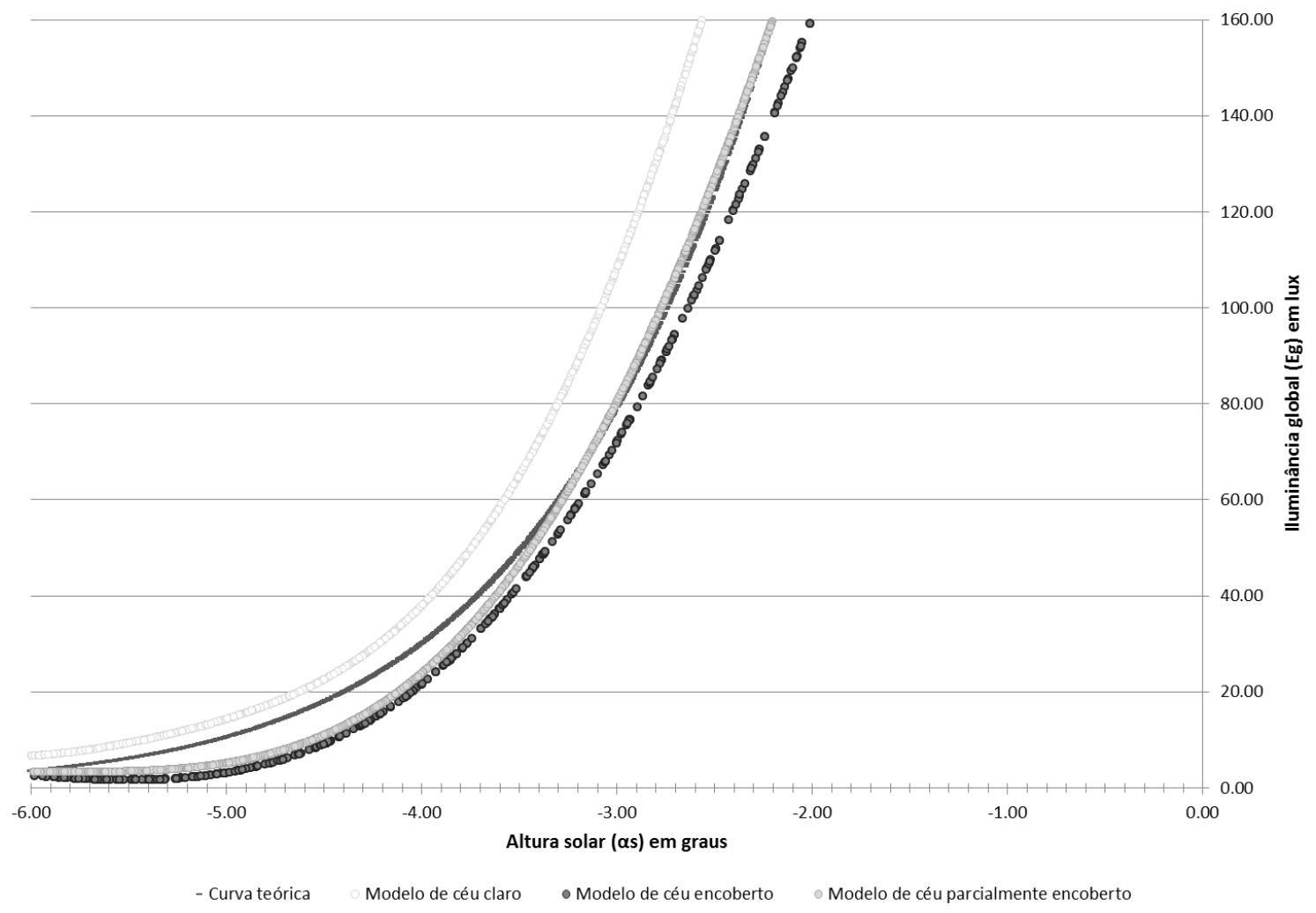

Tabela 9 - Resumo dos modelos polinomiais gerados para cada uma das condições de céu

\begin{tabular}{c|c|c}
\hline Tipo de céu & Equação & $\mathbf{r}^{2}$ \\
\hline Céu claro & $\mathrm{Eg}=-0,4689 \mathrm{x}^{5}-9,8851 \mathrm{x}^{4}-76,622 \mathrm{x}^{3}-247,08 \mathrm{x}^{2}-187,28 \mathrm{x}+387,84$ & 0,95 \\
Céu encoberto & $\mathrm{Eg}=-0,0007 \mathrm{x}^{5}+0,0886 \mathrm{x}^{4}+2,7625 \mathrm{x}^{3}+29,577 \mathrm{x}^{2}+138,07 \mathrm{x}+241,63$ & 0,91 \\
$\begin{array}{c}\text { Céu parcialmente } \\
\text { encoberto }\end{array}$ & $\mathrm{Eg}=-0,1328 \mathrm{x}^{5}-3,1322 \mathrm{x}^{4}-25,653 \mathrm{x}^{3}-72,701 \mathrm{x}^{2}+52,49 \mathrm{x}+421,17$ & 0,94 \\
\hline
\end{tabular}


Tabela 10 - Duração da noite média mensal medida (horas), teórica e dos modelos para a cidade de Belo Horizonte no período de medições

\begin{tabular}{c|c|c|c|c}
\hline Mês & Medido & Teórico & $\begin{array}{c}\text { Modelo para todos } \\
\text { os tipos de céu }\end{array}$ & $\begin{array}{c}\text { Modelo para cada } \\
\text { condição de céu }\end{array}$ \\
\hline Janeiro & $10: 30$ & $10: 22$ & $10: 21$ & $10: 27$ \\
\hline Fevereiro & $10: 54$ & $10: 48$ & $10: 49$ & $10: 50$ \\
\hline Março & $11: 29$ & $11: 22$ & $11: 22$ & $11: 27$ \\
\hline Abril & $12: 01$ & $11: 55$ & $11: 56$ & $12: 00$ \\
\hline Maio & $12: 23$ & $12: 23$ & $12: 23$ & $12: 22$ \\
\hline Junho & $12: 34$ & $12: 36$ & $12: 35$ & $12: 31$ \\
\hline Julho & $12: 28$ & $12: 31$ & $12: 30$ & $12: 32$ \\
\hline Agosto & $12: 05$ & $12: 08$ & $12: 10$ & $11: 41$ \\
\hline Setembro & $11: 37$ & $11: 37$ & $11: 39$ & $11: 08$ \\
\hline Outubro & $11: 08$ & $11: 03$ & $11: 02$ & $10: 36$ \\
\hline Novembro & $10: 37$ & $10: 31$ & $10: 32$ & $10: 18$ \\
\hline Dezembro & $10: 22$ & $10: 14$ & $10: 15$ & $\mathbf{1 1 : 3 0}$ \\
\hline Média anual & $\mathbf{1 1 : 3 1}$ & $\mathbf{1 1 : 2 7}$ & $\mathbf{1 1 : 2 7}$ & \\
\hline
\end{tabular}

Observa-se que há um melhor assentimento entre os valores medidos e modelados para cada condição de céu na maior parte dos meses e na média anual. Já em relação aos valores teóricos, há certa discordância. Os valores modelados para todas as condições de céu aproximam-se bastante dos valores teóricos, provavelmente por ser este modelo desenvolvido para uma condição média.

Calculando a duração da noite para a cidade de Belo Horizonte a partir dos modelos gerados, encontrou-se a duração da noite média anual de 11 h e 30 min. Comparando esse resultado, a duração média da noite para um ano de medição encontrada foi de $11 \mathrm{~h}$ e $32 \mathrm{~min}$ para a mesma cidade (PEREIRA et al., 2009). Essa diferença pode ser decorrente até mesmo de arredondamentos de valores numéricos no próprio Excel ${ }^{\circledR}$.

Analisando a diferença para a duração da noite média mensal entre os valores medidos e preditos, encontrou-se uma diferença entre 0 e 4 min (a mais ou a menos), entre os dados obtidos a partir dos modelos, sendo ainda importante considerar-se a incerteza inerente ao modelo. A tendência observada foi a de que o modelo para cada condição de céu forneceu valores inferiores de duração da noite em relação aos dados medidos. Os meses de agosto e outubro apresentaram os melhores resultados, obtendo-se valores equivalentes entre os modelos para cada condição de céu aos dados medidos. A maior diferença encontrada, $4 \mathrm{~min}$, foi obtida nos meses de fevereiro, julho, setembro e dezembro, sendo os valores obtidos a partir dos modelos para cada condição de céu, nos meses de julho e setembro, de noites maiores.

Considerando a possibilidade de expandir a aplicação dos modelos desenvolvidos a outras cidades de Minas Gerais, testaram-se os modelos por tipo de céu para algumas cidades do estado que continham dados nas Normais Climatológicas (BRASIL, 1992): Lavras; Machado; Montes Claros; Paracatu; e Viçosa.

Essas cidades foram selecionadas por representarem pontos extremos (norte, leste, sul e oeste) do estado e climas diversos entre si.

Aplicou-se, assim como para Belo Horizonte, o método simplificado desenvolvido por Ferreira e Souza (2006), para identificar o céu típico de cada mês para as cidades citadas. A Tabela 11 apresenta os céus típicos para cada uma das cidades.

A seguir, utilizaram-se os modelos para os respectivos tipos de céu, para encontrarem-se os momentos em que os níveis de 80 e 20 lux são atingidos, para, então, a duração da noite ser calculada. A duração da noite encontrada para essas cidades foi comparada com a duração da noite fornecida pelo software Helios, e os resultados estão confrontados na Tabela 12.

Pode-se constatar que há semelhança nos resultados encontrados pelos modelos e pelo Helios para as cidades em que há meses com a condição de céu claro predominante. Já para cidades com um regime de chuvas diferenciado, os valores divergem, sendo os valores preditos superiores aos do Helios. Uma vez que o software Helios apresenta-se como um modelo mais genérico, por basear-se na latitude e pluviosidade local, do que os modelos desenvolvidos com base nas condições de céu, este aparenta proporcionar maior sensibilidade para a variação de disponibilidade de luz natural no período crepuscular. 
Tabela 11 - Céus típicos para as cidades de Minas Gerais avaliadas

\begin{tabular}{c|c|c|c|c|c}
\hline & Lavras & Machado & Montes Claros & Paracatu & Viçosa \\
\hline Janeiro & Encoberto & Encoberto & Parc. encoberto & Encoberto & Encoberto \\
Fevereiro & Parc. encoberto & Encoberto & Parc. encoberto & Encoberto & Parc. encoberto \\
Março & Parc. encoberto & Encoberto & Parc. encoberto & Encoberto & Parc. encoberto \\
Abril & Parc. encoberto & Parc. encoberto & Parc. encoberto & Parc. encoberto & Parc. encoberto \\
Maio & Parc. encoberto & Parc. Encoberto & Claro & Parc. encoberto & Parc. encoberto \\
Junho & Parc. encoberto & Parc. encoberto & Claro & Parc. encoberto & Parc. encoberto \\
Julho & Claro & Parc. encoberto & Claro & Parc. encoberto & Parc. encoberto \\
Agosto & Claro & Parc. encoberto & Claro & Parc. encoberto & Parc. encoberto \\
Setembro & Parc. encoberto & Encoberto & Parc. encoberto & Encoberto & Encoberto \\
Outubro & Parc. encoberto & Encoberto & Parc. encoberto & Encoberto & Encoberto \\
Novembro & Encoberto & Encoberto & Encoberto & Encoberto & Encoberto \\
Dezembro & Encoberto & Encoberto & Encoberto & Encoberto & Encoberto \\
\hline
\end{tabular}

Tabela 12 - Duração da noite pelos modelos desenvolvidos e pelo programa Helios para cidades de Minas Gerais

\begin{tabular}{c|c|c|c}
\hline Cidade & Latitude & Helios & Modelo \\
\hline Lavras & $-21,23^{\circ}$ & $11 \mathrm{~h} 29 \mathrm{~min}$ & $11 \mathrm{~h} \mathrm{30 \textrm {min }}$ \\
Machado & $-21,70^{\circ}$ & $11 \mathrm{~h} 29 \mathrm{~min}$ & $11 \mathrm{~h} 30 \mathrm{~min}$ \\
Montes Claros & $-16,75^{\circ}$ & $11 \mathrm{~h} 29 \mathrm{~min}$ & $11 \mathrm{~h} 29 \mathrm{~min}$ \\
Paracatu & $-17,25^{\circ}$ & $11 \mathrm{~h} 29 \mathrm{~min}$ & $11 \mathrm{~h} 34 \mathrm{~min}$ \\
Viçosa & $-20,74^{\circ}$ & $11 \mathrm{~h} 29 \mathrm{~min}$ & $11 \mathrm{~h} \mathrm{32min}$ \\
\hline
\end{tabular}

\section{Conclusões}

A base de cálculo atual para encargo com iluminação pública é de $12 \mathrm{~h}$ diárias, definidas a partir da média anual de horas entre o pôr e o nascer do sol, considerando a duração média do dia quando o sol encontra-se na linha do horizonte. Entretanto, esse cálculo não considera o período crepuscular, quando há luz no céu, apesar de o Sol encontrar-se abaixo da linha do horizonte.

De fato, a consideração da luz crepuscular pode contribuir para a redução do tempo determinado para a utilização da iluminação pública. Todavia, para tanto, é preciso o conhecimento desse fenômeno e sua quantificação, de forma a possibilitar a correta previsão dos tempos de acionamento de iluminação pública.

Este trabalho propôs-se a determinar os níveis de iluminância da alvorada e do ocaso através de modelos matemáticos de regressão a partir de dados medidos que fossem capazes de quantificar a luz presente no crepúsculo, para, então, definir os períodos necessários de iluminação pública artificial noturna para a cidade de Belo Horizonte.

Para tal, houve um período de monitoramento das condições de céu e de iluminância horizontal pela Estação de Medição de Belo Horizonte (EMIN$\mathrm{BH})$ por tempo suficiente para permitir a modelagem dos tipos de céu e, assim, a previsão das condições da luz crepuscular em sua frequência de ocorrência relativa aos tipos de céu.
Os modelos específicos para cada condição de céu apresentaram melhor desempenho que os modelos para todas as condições de céu. Analisando as curvas de tendência dos modelos por tipo de céu, aquela que mais se aproxima da curva teórica é a curva da condição de céu claro. Os dias de céu claro apresentaram dias de maior duração, sendo seguidos pelo céu parcialmente encoberto e encoberto respectivamente.

Com base nos modelos desenvolvidos, identificaram-se os horários de ocorrência dos valores de iluminância de 20 e 80 lux, valores estes referentes ao momento em que o relé fotoelétrico deve ser acionado ao anoitecer e amanhecer respectivamente, segundo a NBR 5123 (ABNT, 1997), para, por fim, calcular a duração da noite (em horas).

Comparando a duração da noite média mensal medida e predita, observou-se uma diferença entre 0 e 4 min, em função da época do ano. Os resultados encontrados para a duração média anual da noite a partir dos modelos foram satisfatórios, quando a diferença máxima encontrada entre medido e predito foi de $4 \mathrm{~min}$, havendo, ainda, que se considerarem as incertezas das medições e dos próprios modelos, valor pouco significante e provavelmente decorrente da variação de umidade presente na atmosfera entre os dias medidos, evidenciando a necessidade de incorporar ao modelo uma terceira variável, capaz de caracterizar a umidade presente na atmosfera terrestre. Recomenda-se para trabalhos futuros a 
investigação de uma variável capaz de caracterizar a umidade contida na atmosfera de forma adequada, uma vez que a inserção do conteúdo de vapor de água não se mostrou satisfatória.

A duração média anual da noite para a cidade de Belo Horizonte foi de $11 \mathrm{~h}$ e 32 min para o intervalo de 20 a 80 lux. A duração média anual da noite para a mesma cidade a partir dos modelos gerados foi de $11 \mathrm{~h}$ e $30 \mathrm{~min}$, portanto valores bastante próximos, o que verifica a capacidade de predição dos modelos. No que se refere à curva teórica, a duração da noite encontrada a partir dessa curva, de 11 h e $27 \mathrm{~min}$, valor inferior à duração da noite medida e predita, evidenciou não ser o modelo teórico o mais adequado para a estimativa da duração da noite.

Os modelos desenvolvidos para a cidade de Belo Horizonte, quando aplicados em outras cidades do Estado, apontaram bom desempenho para cidades com a condição de céu claro predominante, sendo encontrados valores próximos ao software Hélios, para a duração da noite. No entanto, para cidades com um regime de chuvas diferenciado, os modelos desenvolvidos apresentaram maior sensibilidade para as variações da disponibilidade de luz natural do que o software.

É importante ressaltar que o resultado encontrado refere-se à condição de céu desobstruído, como a da estação medidora EMIN-BH. Entretanto, a linha do horizonte local pode ser afetada pelo relevo (ocorrência de elevações ou montanhas), assim como pela paisagem urbana, em seu processo de verticalização, resultando em menor disponibilidade de luz natural na abóbada celeste local, ocorrendo o nascer do sol mais tarde, e o pôr do sol, mais cedo, com a necessidade de considerarem-se essas variações no cálculo da duração da noite. Como trabalhos futuros, sugerese a investigação do impacto do relevo e da paisagem urbana na disponibilidade de luz natural no período crepuscular e, consequentemente, na duração da noite.

\section{Referências}

ASSOCIAÇÃO BRASILEIRA DE NORMAS TÉCNICAS. NBR 5123: rele fotoelétrico para iluminação: especificação e método de ensaio. Rio de Janeiro, 1997.

\section{ASSOCIAÇÃO BRASILEIRA DE NORMAS} TÉCNICAS. NBR 15215-2: iluminação natural parte 2: procedimentos de cálculo para a estimativa da disponibilidade de luz natural. Rio de Janeiro, 2005.
AGÊNCIA NACIONAL DE ENERGIA ELÉTRICA. Resolução ANEEL no 456.

Disponível em:

<http://www.aneel.gov.br/cedoc/bres200456.pdf>. Acesso em: 23 mar. 2008.

\section{ARREGUY, E. G. Garantia da Qualidade}

Metrológica das Medições de Iluminância das Estações. 112 f. Belo Horizonte, 2008.

Dissertação (Mestrado em Engenharia Mecânica)

- Programa de Pós-Graduação em Engenharia

Mecânica, Pontifícia Universidade Católica de

Minas Gerais, Belo Horizonte, 2008.

BRASIL. Normais Climatológicas (1961-1990). Brasília, DF: Instituo Nacional de Meteorologia, 1992.

DUFFIE, J. A.; BECKMAN, W. Solar

Engineering of Thermal Processes. New Jersey: John Wiley\&Sons, 2006.

FERREIRA, F. D.; SOUZA, R. V. G. D.

Determinação de Céus típicos Para Minas Gerais: metodologia de obtenção a partir de dados simplificados. In: ENCONTRO NACIONAL DE TECNOLOGIA NO AMBIENTE CONSTRUÍDO, 11., São Paulo, 2006. Anais... São Paulo: ANTAC, 2006.

INTERNATIONAL DAYLIGHT MEASUREMENT PROGRAMME. The IDMP

Network. Disponível em: <http://idmp.entpe.fr/index.html>. Acesso em: 17 jun. 2008

MUNEER, T. Solar Radiation and Daylight Model. London: Elsevier, 2004.

PEREIRA, E. M. D. et al. Estudo da

Disponibilidade de Luz Natural em Belo

Horizonte Como Base Para Programação da

Iluminação Pública Artificial Noturna. Belo Horizonte: GREEN Solar PUC Minas, Labcon EA/UFMG, CEMIG, 2009. 26 p.

PROGRAMA NACIONAL DE CONSERVAÇÃO DE ENERGIA ELÉTRICA

Procel. 2008. Disponível em:

<http://www.eletrobras.com/elb/procel/main.asp>. Acesso em: 13 jul. 2009.

SEIDELMAN, P. Explanatory Supplement to the Astronomical Almanac. Sausalito: University Science, 2006. 


\section{Camila Carvalho Ferreira}

Departamento de Tecnologia da Arquitetura e do Urbanismo, Escola de Arquitetura | Universidade Federal de Minas Gerais | Rua Paraíba, 697, sala 124, Funcionários | Belo Horizonte - MG - Brasil | CEP 30130-140 | Tel.: (31) 3409-8872 |

E-mail: camilaccferreira@yahoo.com.br

\section{Roberta Vieira Gonçalves Souza}

Departamento de Tecnologia da Arquitetura e do Urbanismo, Escola de Arquitetura | Universidade Federal de Minas Gerais | Rua Paraíba 697, sala 124, Funcionários | Belo Horizonte - MG - Brasil | CEP 30130-140 | Tel.: (31) 3409-8872 | E-mail: robertavgs2@gmail.com

\section{Revista Ambiente Construído}

Associação Nacional de Tecnologia do Ambiente Construído

Av. Osvaldo Aranha, $99-3^{\circ}$ andar, Centro

Porto Alegre - RS - Brasil

CEP $90035-190$

Telefone: +55 (51) 3308-4084

Fax: +55 (51) 3308-4054

www.seer.ufrgs.br/ambienteconstruido

E-mail: ambienteconstruido@ufrgs.br 